\title{
A participação política das crianças pequenas na autoavaliação da qualidade da educação infantil: contribuições desde Paulo Freire
}

\author{
Agleide de Jesus Vicente* - USCS \\ Marta Regina Paulo da Silva** - USCS
}

\section{Resumo}

O artigo compartilha a experiência de uma creche da Rede Municipal de São Paulo que vem construindo práticas que viabilizem a participação das crianças pequenas no processo de autoavaliação institucional. Defende, à luz das contribuições de Paulo Freire, as crianças como sujeitos de direitos, dentre eles o direito à palavra e à participação, bem como as instituições de educação infantil como espaços propícios para se viver experiências democráticas. A metodologia adotada foi a indicada no documento "Indicadores de Qualidade da Educação Infantil Paulistana", sendo esta adaptada às crianças pequenas através do uso de fotografias e de rodas de conversas. Conclui que as crianças leem e dizem o mundo de um modo muito singular, o que implica na ruptura da cultura adultocêntrica para que, desde uma perspectiva dialógica, suas vozes sejam consideradas. Vozes que demostram preocupação com o bem comum, o que denota sua importância na construção da qualidade social da educação infantil.

Palavras-chave: Paulo Freire. Criança. Participação Política. Autoavaliação Institucional. Creche.

* Graduação em Pedagogia pela UniABC, pós graduada em Educação Infantil e Alfabetização e Letramento pela Universidade Metodista de São Paulo. Cursando Mestrado Profissional em Educação pela USCS. É coordenadora pedagógica e atualmente exerce a função de Assistente Técnico de Educação I na DIPED-EI - SM, realizando atividades voltadas à formação de Gestores e Professores da Educação Infantil. E-mail: agleide2014@gmail.com

** Doutora em Educação pela UNICAMP. Docente e Pesquisadora no Programa de Pós-graduação em Educação da Universidade de São Caetano do Sul-USCS. E-mail: martarps@uol.com.br 


\section{The political participation of young children in the self-assessment of childhood education quality: contributions since Paulo Freire}

\section{Abstract}

This article shares the experience of a Nursery School of the Municipal Educational System of São Paulo that has been building practices that enable the participation of young children in the process of institutional self-assessment. In the light of Paulo Freire's contributions, it defends children as subjects of rights, such as speech and participation, as well as Early Childhood Educational Institutions as propitious spaces to live democratic experiences. The methodology adopted was that indicated in the document "Quality Indicators of Early Childhood Education in São Paulo", which was adapted to young children through the use of photographs and conversation circles. It concludes that children read and tell the world in a very unique way, which implies the rupture of the adult-centric culture so that, from a dialogical perspective, their voices are considered. Voices that show concern for the common good, which denotes its importance in building the social quality of early childhood education.

Keywords: Paulo Freire. Child. Political Participation. Institutional Self-Assessment. Nursery.

\section{La participación política de los niños pequeños en la autoevaluación de la calidad de la educación infantil: contribuciones desde Paulo Freire}

\section{Resumen}

El artículo comparte la experiencia de una guardería en la Red Municipal de São Paulo que ha estado construyendo prácticas que permiten la participación de niños pequeños en el proceso de autoevaluación institucional. A la luz de las contribuciones de Paulo Freire, defiende a los niños como sujetos de derechos, entre ellos el derecho al habla y la participación, así como a las instituciones de educación de la primera infancia como espacios propicios para vivir experiencias democráticas. La metodología adoptada fue la indicada en el documento "Indicadores de calidad de la educación infantil en São Paulo”, la cual fue adaptada a los niños pequeños mediante el uso de fotografías y círculos de conversación. Se concluye que los niños leen y cuentan el mundo de una manera muy singular, lo que implica la 
ruptura de la cultura centrada en el adulto para que, desde una perspectiva dialógica, se consideren sus voces. Voces que manifiestan preocupación por el bien común, lo que denota su importancia en la construcción de la calidad social de la educación infantil.

Palabras clave: Paulo Freire. Niño. Participacion Politica. Autoevaluación institucional. Guardería.

\section{Introdução}

Bom amigo Malaguzzi,

Menino eterno, pede-me, antes de eu retornar ao Brasil que escreva algumas palavras dedicadas às meninas e aos meninos italianos. Não sei se saberia dizer algo de novo a um tal pedido. O que poderia dizer ainda aos meninos e às meninas deste final de século? Primeira coisa, aquilo que posso dizer em função da minha longa experiência nesse mundo, é que devemos fazê-lo sempre mais bonito. E baseando-me em minha experiência que torno a dizer, não deixemos morrer a voz dos meninos e das meninas que estão crescendo. Paulo Freire, abril, 1990 (FREIRE apud FARIA; SILVA, 2013, p. 101)

A defesa de Paulo Freire ao direito das crianças à sua palavra o acompanha em seu trabalho como educador. Já no final da década de 1950, esse educador pernambucano defendia a criança como sujeito de direitos, afirmando que as primeiras experiências participativas e de decisão de meninos e meninas deveriam ser iniciadas no ambiente familiar prolongando-se às escolas (FREIRE, 2001). Nessas experiências de exercício democrático, adultos(as) e crianças estabeleceriam uma relação horizontal mediada pelo mundo, reconhecendo um ao outro em sua alteridade.

Sabemos que a criança, no decorrer da história, foi compreendida como o sujeito da falta, imatura, passiva, sem direito à voz e à participação nos diferentes contextos aos quais estivesse inserida, daí ser cuidada, educada e disciplinada a partir dos valores, crenças e conhecimentos do mundo adulto, que, determinados pelo contexto sócio-histórico-cultural, a considerou tão somente como reprodutora da cultura. A partir do século XX, em função das mudanças históricas, sociais, políticas e culturais, meninos e meninas 
começam a ser reconhecidos(as) como sujeitos históricos, sociais, com uma razão infantil diferente da racionalidade adulta, e que constroem conhecimento por meio das relações e interações que estabelecem com o meio, físico e social, não apenas reproduzindo, mas também produzindo cultura, lendo e dizendo o mundo de um jeito próprio, por meio de suas múltiplas linguagens.

No Brasil, a promulgação da Constituição Federal de 1988 (BRASIL, 1988) legitimou e deu visibilidade às crianças como sujeitos de direitos, sendo reafirmada na Convenção dos Direitos da Criança de 1990 (BRASIL, 1990), que, além de assegurar os direitos à provisão e à proteção, assegura à criança o direito à voz e que sua opinião seja considerada em situações que lhe dizem respeito, reconhecendo-a como ator social com capacidade de participação na sociedade, ou seja, cidadã que transforma e é transformada pelo mundo.

Contudo, mesmo diante dos novos contornos acerca da compreensão da criança e seu direito à participação, encontramos em muitas instituições de educação infantil um espaço de contradição, ainda permeado pela concepção reacionária de que meninos e meninas são como "tábulas rasas", sendo suas vozes silenciadas por meio do julgamento do(a) adulto(a), quase sempre marcado pela descrença na potencialidade da infância, afirmando serem as crianças incapazes de analisar ou inferir percepções sobre os contextos aos quais estão inseridas. Cabe ponderar também, se tal postura autoritária não se justifica pelo receio das vozes das crianças, de suas perguntas; como pontua Freire (2017, p. 68), “[...] a impressão que tenho é a de que, em última análise, o educador autoritário tem mais medo da resposta do que da pergunta. Teme a pergunta pela resposta que deve dar".

O silenciamento das vozes infantis expressa uma das formas de colonialismo em que o(a) adulto(a) impõe sobre as crianças a sua leitura de mundo. Isso se observa em muitas práticas presentes nas instituições de educação infantil (SILVA, 2017, 2020), dentre elas a da autoavaliação institucional, realizada em muitos municípios brasileiros. Especificamente sobre o processo de autoavaliação institu- 
cional com crianças pequenas, poucos são os estudos e pesquisas que se debruçam sobre esta temática. Em consulta à base de dados das plataformas Capes-Coordenação de Aperfeiçoamento de Pessoal de Nível Superior e BDTD-Biblioteca Digital Brasileira de Teses e Dissertações, foram identificados quatro títulos que tratam da participação das crianças no planejamento das cotidianidades como um processo democrático, considerando a potencialidade infantil e suas vozes no planejamento pedagógico e institucional. Destes trabalhos, apenas a dissertação de Emilly Rosa, 2015 "O planejamento democrático e participativo construído com as crianças de 0 a 3 anos", trata do processo participativo de crianças bem pequenas na creche, como um espaço democrático, reconhecendo-as como sujeitos de direitos e participativos.

Na cidade de São Paulo, a autoavaliação institucional ocorre anualmente, por meio do instrumento Indicadores de Qualidade da Educação Infantil Paulistana (SÃO PAULO, 2016), e deveria contar com a participação de todos os atores da comunidade educativa, incluindo os bebês e as crianças pequenas, com o objetivo de garantir uma educação infantil de qualidade. Contudo, a participação dos bebês e das crianças pequenas não acontece, pois muitos(as) adultos(as) não acreditam na potencialidade desses meninos e meninas em compartilhar suas hipóteses, teorias, impressões, desejos ou necessidades "[...] como elementos importantes para a (re)organização das ações” (SÃO PAULO, 2016, p. 35) na unidade educativa.

Escutar as crianças e compreender o mundo a partir dos seus olhos implica no rompimento desse silenciamento, e, consequentemente, na construção de uma relação dialógica com elas, reconhecendo-as como participantes ativas da e na sociedade, o que se constituiu como um grande desafio frente a esta sociedade adultocêntrica.

Face a esse desafio, este artigo objetiva compartilhar a experiência de uma creche da Rede Municipal de Educação de São Paulo, que vem procurando garantir a participação das crianças pequenas no processo de autoavaliação institucional, construindo 
uma relação dialógica entre crianças e adultos(as) e a creche como um espaço de participação coletiva, a fim de "[...] transformar a realidade, para nela intervir, recriando-a” (FREIRE, 1996, p. 76).

A interlocução se faz a partir das contribuições de Paulo Freire em diálogo com outros(as) estudiosos(as) da área da infância, no intuito de pensar esta criança cidadã e o seu direito à participação política na sociedade e, em especial, no cotidiano das instituições de educação infantil. Cabe pontuar que o momento é propício para nos debruçarmos sobre a epistemologia freiriana na reflexão sobre a prática pedagógica, visto vivermos um período em que as forças conservadoras procuram amordaçar e silenciar não apenas as crianças, mas também seus educadores e educadoras. Nesse sentido, a atualidade do pensamento de Paulo Freire nos convoca à necessidade política de reinventá-lo, para que possamos responder aos desafios deste tempo histórico.

\section{Creche: um coletivo de relações, interações e contradições}

A creche, onde este trabalho foi realizado, está situada em um bairro periférico da região Leste do município de São Paulo, atende 141 crianças com idade de 0 a 3 anos e 11 meses em período integral de 10 horas, cada agrupamento conta com a regência de duas professoras em períodos distintos, manhã e tarde. A instituição dispõe de um espaço externo privilegiado, com área verde, parque, tanque de areia, solário, e o espaço interno dispõe de 10 salas de referência e o refeitório.

Nessa instituição, assim como outras no município de São Paulo, todo início de ano a equipe educativa reunida apresenta-se com muitas ideias, expectativas e planos, pois é chegada a hora de discutir, definir, planejar e redimensionar o Projeto Político Pedagógico a partir das avaliações do ano anterior, do conhecimento do território, das crianças e suas respectivas famílias, das culturas que permeiam suas vivências, do que elas esperam da creche e o que se espera delas, sempre com discursos permeados de muita teoria, crenças, e certezas; muitas certezas. 
Eis aqui um grande problema, as muitas certezas, o que termina por não permitir abertura às dúvidas, aos questionamentos, às incertezas, ao novo, ao diálogo, à escuta do(a) outro(a), à certeza do(a) outro(a), o que, por sua vez, culmina na elaboração de um planejamento fechado e inflexível, demonstrando o abismo ainda existente entre essas duas instituições: creche e família, e também entre os(as) adultos(as) e as crianças.

Larrosa (2003, p. 184) nos instiga a pensar o quanto "[...] a infância é algo que nossos saberes, nossas práticas e nossas instituições já capturaram", questiona sobre o espaço da inquietação, do questionamento e do vazio para que possamos reconhecer a infância como um outro, reconhecê-la em sua alteridade, em sua "absoluta diferença". Freire, em 1979, respondendo a uma pergunta acerca de ser marxista, dizia: "Não fui às classes oprimidas por causa de Marx. Fui à Marx por causa deles. $\mathrm{O}$ meu encontro com eles é que me fez encontrar Marx e não o contrário" (FREIRE apud GADOT'TI, 1996, p. 609).

Ir ao encontro do(a) outro(a), com abertura e inquietação, reconhecendo que nenhum saber ou prática é capaz de capturá-lo(a). Afinal, como dialogar quando a arrogância do saber não deixa espaço para o encontro? Nas palavras de Freire (1987, p. 46): "Como posso dialogar, se me sinto participante de um "gueto" de homens puros, donos da verdade e do saber, para quem todos os que estão fora são "essa gente", ou são "nativos inferiores"? Como posso dialogar, se me fecho à contribuição dos outros, que jamais reconheço, e até me sinto ofendido com ela?’”.

Creches e pré-escolas se apropriam do discurso em defesa de uma criança potente, criativa, sujeito de direitos, produtora de cultura, capaz de provocar mudanças nos contextos em que estão inseridas. Citam em seus documentos institucionais que suas ações estão em conformidade com as Diretrizes Curriculares Nacionais para Educação Infantil - DCNEI (BRASIL, 2010), com o objetivo de formar cidadãs/cidadãos críticas(os) e participativas(os), "[...] com direito à voz, à escolha e a tomada de decisões” (SÃO PAULO, 2016, 
p. 12). No entanto, o discurso da criança potente e participativa não encontra eco no cotidiano de muitas instituições em que se observam práticas antidialógicas, centralizadas no(a) adulto(a), através de pedagogias transmissivas, bancárias (FREIRE, 1987), em que os bebês e crianças são apenas receptores(as) de informações e culturas dos(as) adultos(as), privados(as) de exercerem os seus direitos.

Romper com a distância entre discurso e prática constitui-se em um grande desafio. Larrosa (2003) nos dá pista ao defender que o(a) adulto(a) precisa assumir-se no lugar do não saber, reconhecendo a alteridade da infância, a criança como um outro único e singular, que questiona, que subverte a lógica adulta de ver o mundo querendo descobri-lo, portanto, nós adultos(as), precisamos estar abertos(as) a aprender com ela, acreditar em sua capacidade de argumentar, sugerir, criticar, opinar, analisar e interpretar os contextos em que convivem. Segundo Freire (1992, p. 44), meninos e meninas, ao chegarem na escola, [...] trazem consigo de compreensão de mundo, nas mais variadas dimensões de sua prática na prática social de que fazem parte. Sua fala, sua forma de contar, de calcular, seus saberes em torno de chamado outro mundo [...]". Há uma razão infantil naquilo que as crianças dizem e fazem, sendo necessário reconhecer que, somos seres, desde que nascemos, capazes de não apenas captar dados da realidade, mas de observar entre eles nexos causais. Assim:

Razão infantil é entendida aqui como a visão de mundo das crianças, como a faculdade humana de criar estruturas ideativas a partir de suas impressões, sentimentos e compreensões do seu entorno. Na razão infantil, a linguagem não é hierarquizada por uma norma externa previamente estabelecida, mas se efetiva por diferentes formas de expressão em que a corporeidade não fragmenta as sensações, as emoções, a cognição. (SILVA, 2020, p. 5)

Face às inquietudes e contradições que adentram o universo da educação infantil, em especial, a creche, a Rede Municipal de Educação de São Paulo implementou, a partir de 2015, o processo de autoavaliação institucional participativa, mediada pelo instru- 
mento IQEIP (SÃO PAULO, 2016), que tem por objetivo, auxiliar as equipes educativas " [...] a desenvolver um processo de autoavaliação institucional participativa que leve a um diagnóstico coletivo sobre a qualidade da educação promovida em cada Unidade, de forma a obter melhorias no trabalho educativo desenvolvido com as crianças" (SÃO PAULO, 2016, p. 7).

Esse processo inclui a participação da comunidade educativa (crianças, famílias, docentes, gestores(as), equipe de apoio, auxiliares de limpeza e cozinha, assim como representantes da comunidade), para que, no coletivo, possa discutir, planejar, executar ou encaminhar à outras instâncias ações que visem qualificar o atendimento aos bebês e às crianças pequenas.

O documento Indicadores de Qualidade da Educação Infantil Paulistana - IQEIP (SÃO PAULO, 2016) é constituído por 9 dimensões consideradas fundamentais à qualidade da educação infantil paulistana, estando estas articuladas com a realidade das instituições de educação infantil do município de São Paulo, como afirma Ribeiro, Campos e Valverde (2015), sendo elas: Planejamento e Gestão educacional; Participação, escuta e autoria dos bebês e crianças; Multiplicidade de experiências e linguagens com contextos lúdicos para as infâncias; Interações; Relações étnico-raciais e de gênero; Ambientes educativos: espaços, tempos e materiais; Promoção da saúde e bem-estar: experiências de ser cuidado, cuidar de si, do outro e do mundo; Formação e condições de trabalho dos educadores e das educadoras; Rede de proteção sócio cultural: Unidade Educacional, família, comunidade e cidade.

Para Bondioli (2004), a vivência desse processo de autoavaliação participativa pode constituir-se em um momento formativo, pois todos(as) os(as) autores(as) daquela unidade educativa constroem conhecimento, o conceito de qualidade para aquele território em parceria, em uma relação dialógica, considerando suas fragilidades e potencialidades, em uma proposição horizontal, valorizando a escuta de todos os sujeitos incluindo as crianças, estabelecendo uma reflexão contínua de acompanhamento e qualificação das práticas 
educativas e do Projeto Político Pedagógico da unidade através da construção do plano de ação em que todos(as) são corresponsáveis.

Considerando o direito à participação de todos os atores que integram a comunidade educativa, conforme assevera o documento IQEIP (SÃO PAULO, 2016), como garantir a participação das crianças pequenas no processo de autoavaliação institucional?, sobretudo diante das manifestações da própria equipe docente e gestora de que "As crianças são muito pequenas para participar de um processo de autoavaliação"; "As crianças não têm maturidade para avaliar a creche".

Viver a cultura democrática implica diminuir a distância hierárquica entre adultos(as) e crianças, pois é vivenciando essas experiências que meninos e meninas vão construindo uma leitura crítica da realidade e se constituindo enquanto sujeitos transformadores da sociedade. Nesse sentido, creches e pré-escolas precisam se reconhecer como espaços de participação, espaços dialógicos em que todos e todas têm direito a dizer sua palavra (FREIRE, 2001), em uma relação em que adultos(as) e crianças são protagonistas do processo, com responsabilidades partilhadas.

Na dialética denúncia-anúncio, Freire (1987), ao denunciar a educação bancária, anuncia a proposição de uma outra educação, a educação como prática da liberdade. Sua proposta implica em uma “[...] escuta atenta e sensível do(a) educando(a), ao respeito à sua cultura, ao reconhecimento do direito à sua palavra, à perspectiva da construção de uma educação para a libertação; o que nos anima a pensá-la, (re)inventá-la, para a educação de crianças pequenas" (SILVA; MARQUES, 2019, p. 8).

Pensar uma educação na perspectiva da emancipação das crianças, pressupõe confiar nelas, em sua capacidade de ler o mundo e de dizer a sua palavra a partir de suas múltiplas linguagens. Daí Freire (apud FREIRE; GUIMARÃES, 1984) defender que o(a) educador(a) estimule o gosto das crianças pelas artes, pelos meios de comunicação, pela leitura e escrita; e que respeite o seu direito à brincadeira. $\mathrm{O}$ intuito é que meninos e meninas avancem em seu 
conhecimento do mundo e que o façam de maneira participativa e investigativa.

Reconhecendo esse direito de meninos e meninas à participação nas decisões da instituição, a creche, aqui estudada, vem construindo um processo participativo com as crianças pequenas. O trabalho foi provocado pelas próprias crianças, no período em que a comunidade educativa realizava o planejamento dos gastos das verbas federais e municipais. Nesse período, uma professora do minigrupo II, de crianças de 3 anos, desenvolvia um projeto com o propósito de que meninos e meninas conhecessem melhor os(as) funcionários(as) da creche, visitando seus ambientes de trabalho e realizando entrevistas, a fim de compreenderem quais eram suas atribuições e reconhecerem a importância de cada um(a) no funcionamento e rotina da instituição.

No transcorrer do projeto, as crianças visitaram a sala da equipe gestora, onde, naquele horário, estava presente apenas a diretora, e perguntaram o que ela estava fazendo. Esta respondeu que planejava o que iria comprar para a creche. Nesse momento, as crianças reivindicaram: "queremos um lugarpara brincar em dia de chuva". A diretora, então, disse à elas que iria anotar a solicitação e recalcular os gastos no intuito de poder atender a tal pedido. Posteriormente, compartilhou com a coordenadora pedagógica a experiência que havia vivenciado com as crianças. A reinvindicação delas transformou e ampliou o olhar das gestoras diante das potencialidades da infância, pois as crianças estavam demonstrando o quanto eram capazes de avaliar as fragilidades que existiam no espaço institucional, espaço que é delas.

Diante desse fato, a equipe gestora refletiu sobre suas concepções de infância, inquietadas pelas seguintes questões: Escutamos os bebês e as crianças em nossa instituição? O que os pequenos e pequenas têm nos dito? $\mathrm{O}$ que aprendemos através dessa escuta? Entendendo que:

A escuta não é fácil. Exige uma profunda consciência e a suspensão dos nossos julgamentos e, acima de tudo, de nossos preconceitos, demanda 
abertura à mudança. Requer que tenhamos claro em nossa mente o valor do desconhecido e que sejamos capazes de superar a sensação de vazio e precariedade que experimentamos sempre que nossas certezas são questionadas. (RINALDI, 2014, p. 125)

Assumir a sensação de vazio e precariedade frente ao questionamento das certezas, não significa negar a autoridade do(a) educador(a), responsável por qualificar os espaços da creche, garantindo a segurança e bem-estar de todos(as), bem como oportunizando bons contextos educativos que favoreçam as experiências das crianças, mas entender que meninos e meninas têm conhecimentos diferentes, que podem contribuir para a constituição do espaço coletivo participando ativamente das decisões do cotidiano, o qual estão implicadas diretamente, pois a escuta de suas vozes não é uma concessão é um direito. Concordando com Freire (1987, p. 46), “[...] não há também, diálogo, se não há uma fé intensa nos homens. Fé no poder de fazer e refazer. De criar e recriar. Fé na sua vocação de ser mais, que não é o privilégio de alguns eleitos, mas o direito de todos os homens".

Perante essas reflexões, a equipe gestora passou a pensar na possibilidade de realizar esse processo de autoavaliação institucional com as crianças do minigrupo II, buscando uma forma de adaptar o documento IQEIP (SÃO PAULO, 2016) para que pudesse escutar os meninos e as meninas.

\section{A escuta que permeia, modifica e transforma a ação educativa}

A proposta de viabilizar a participação das crianças na autoavaliação institucional através dos IQEIP (SÃO PAULO, 2016) iniciou-se com uma reflexão sobre o quanto os planejamentos dos(as) docentes dialogavam com suas concepções discursivas sobre os bebês e as crianças pequenas, enquanto sujeitos de direitos, participativos, observadores, produtores de cultura e conhecimento, e o quanto estava sendo garantida a participação desses pequenos e pequenas na construção do planejamento das cotidia- 
nidades, o que consideravam como escuta, e o que os(as) levavam a escutar o(a) outro(a).

A reflexão crítica do(a) educador(a) sobre sua própria prática é um dos saberes propostos por Freire (1996), o que implica em um movimento dialético entre o fazer e o pensar sobre o fazer. Ela não acontece por um passe de mágica, mas por um processo permanente de formação. Nas palavras do autor: "É pensando criticamente a prática de hoje ou de ontem que se pode melhorar a próxima prática. O próprio discurso teórico, necessário à reflexão crítica, tem que ser de tal modo concreto que quase se confunda com a prática." (FREIRE, 1996, p. 43-44).

Nesse sentido, esse movimento reflexivo da equipe educativa da creche revisitando o próprio fazer, permitiu observar que a participação das crianças nos contextos sociais é implicada pela ação do(a) adulto(a), que precisa se modificar frente às crianças, acreditando, de fato, na potencialidade infantil, pois "[...] trata-se de assumir que a escuta do ponto de vista das crianças significa reconhecer a competência, a participação e protagonismo delas nas cidades, nas decisões políticas, nas pesquisas, na ciência, na educação e em diferentes espaços sociais" (DELGADO, 2013, p. 27).

Freire (1987) pontua que a relação entre educandos(as) e educadores(as) precisa ser firmada e construída pela confiança, pois quando se confia há escuta do(a) outro(a), há abertura ao diálogo, isso porque: “[...] se a fé nos homens é um dado a priori do diálogo, a confiança se instaura nele. A confiança vai fazendo os sujeitos dialógicos cada vez mais companheiros na pronúncia do mundo" (FREIRE, 1987, p. 46). Sendo assim, cabe a nós, adultos(as), construirmos vínculos de confiança com as crianças, que possamos realmente acreditar em suas potencialidades, estabelecendo uma relação dialógica e horizontal, em um processo coletivo de construção de uma instituição pública de qualidade, visto que, a participação infantil em contexto educacional "[...] não é uma mera estratégia pedagógica nem um modismo [...] é um desiderato político e social correspondente a uma renovada concepção de infância como 
geração constituída por sujeitos ativos com direitos próprios [...] e um eixo de renovação da escola pública [...]". (SARMENTO; FERNANDES; TOMÁS, 2007, p. 197)

Face à estas discussões, a equipe gestora junto aos(às) professores(as) pensaram na possibilidade de realizar esse processo de autoavaliação com as crianças do minigrupo II, buscando adaptar o IQEIP (SÃO PAULO, 2016), de modo a construir uma metodologia que viabilizasse a avaliação dos espaços da creche, pois era o que as crianças apontavam como a maior necessidade de qualificação. Como afirma Tonucci (2005, p. 18):

Escutar significa precisar da contribuição do outro. Não basta haver interesse, motivação, convicção de seja uma boa técnica para envolver as crianças; é preciso sentir, sincera e urgentemente, essa necessidade. É necessário precisar das crianças. Esta é a primeira e verdadeira condição para que se possa conceder a palavra às crianças: reconhecer que são capazes de dar opiniões, ideias e de fazer propostas úteis para nós, adultos, capazes de nos ajudar a resolver nossos problemas. Se assim for, a relação com elas será correta, entre cidadãos adultos e pequenos cidadãos, mas, agora, cidadãos.

Para escutar o(a) outro(a) é preciso silenciar-se. No diálogo com as crianças pequenas, o silêncio possibilita escutar não apenas suas falas, mas também seus gestos, movimentos, olhares, expressões; o que não significa omissão ou abandono por parte dos(as) adultos(as), mas um profundo respeito à capacidade das crianças e às suas formas de pensar e agir no mundo (SILVA, 2017). A importância desse silêncio também é defendida por Freire (1996, p. 132):

A importância do silêncio no espaço da comunicação é fundamental. De um lado, me proporciona que, ao escutar, como sujeito e não como objeto, a fala comunicante de alguém, procure entrar no movimento interno do seu pensamento, virando linguagem; de outro, torna possível a quem fala, realmente comprometido com comunicar e não com fazer puros comunicados, escutar a indagação, a dúvida, a criação de quem escutou. Fora disso, fenece a comunicação. 
Silenciar-se para escutar as crianças, de modo a estabelecer um diálogo com elas, não significa negar a voz dos(as) educadores(as), mas aprender com elas.

Em conversas com os(as) professores(as) do minigrupo II, planejou-se que a avaliação ocorreria por meio de rodas de conversa, tendo como disparador as fotografias dos espaços da creche (sala de referência, solário, parque, área externa, refeitório e sala de TV) tiradas pelos(as) próprios(as) docentes. Com relação a metodologia das cores utilizada pelo IQEIP (SÃO PAULO, 2016), em que a cor verde é estabelecida para as práticas e ações na unidade educativa que já estão consolidadas, a cor amarela para as situações e práticas que ocorrem de vez em quando e o vermelho para as situações e ações que não existem na instituição, para as crianças optou-se em utilizar apenas as cores vermelha com a carinha triste para os espaços que não gostavam, e a cor verde com a carinha feliz para os espaços que gostavam, trazendo um aspecto lúdico para este momento de avaliação. Inicialmente as crianças elegeriam o espaço que mais gostavam e depois avaliariam individualmente, identificando se gostavam ou não, e se haveria algo naquele espaço que necessitaria de melhoria ou mudança. A equipe educativa também considerou importante que esse processo de avaliação e escuta das crianças fosse mediado pelo(a) professor(a) de referência, pois é esse(a) adulto(a) que conhece a identidade do grupo e suas culturas, contribuindo para a interpretação da complexidade das vivências infantis.

Visto que as crianças leem e dizem o mundo de um jeito muito peculiar, o que exige do(a) professor(a) adentrar o universo infantil como parceiro(a) para captar as vozes infantis, a equipe decidiu que o registro seria feito por meio da gravação de áudio, assim não perderiam nenhum detalhe de suas falas, o que permitiria o(a) adulto(a) estar em relação com as crianças, observando seus gestos, olhares e significações. O registro funcionaria então como a tessitura da memória compreensiva que, segundo Ostetto (2012, p. 21), “[...] não é simples recordação do que aconteceu, lembranças vãs, mas é a base para refletir sobre o passado, avaliar ações". 
Outra questão discutida no grupo de professores(as), provocada pela equipe gestora, foi a vulnerabilidade infantil, no sentido de que os(as) adultos(as), pais, mães, professores(as) são responsáveis pelas crianças, e que elas precisam ter a garantia de seus direitos de participação nos processos decisórios, bem como ter assegurados seus direitos de proteção.

Sendo assim, para que se efetivasse a participação dos meninos e meninas no processo de autoavaliação da creche, garantindo seus direitos de proteção, era preciso que eles(as) tivessem a liberdade e vontade de participar, sendo informados(as) sobre o que e para que estavam participando, bem como os(as) adultos(as) soubessem que, ao empoderar e dar visibilidade às vozes infantis, não se ouviria apenas o que lhes agradaria, mas que seria um momento de descortinar o que muitas vezes os olhos não querem ver.

\section{A autoavaliação da creche pelo olhar da criança}

O processo de autoavaliação foi vivenciado pelos três agrupamentos de minigrupo II, sendo cada um constituído com dezoito crianças na idade de três anos. Para a avaliação, foram organizados pequenos grupos, com cinco crianças por vez, que eram convidadas a participarem. A roda de conversa foi conduzida pela professora de referência, seguindo o que defende Tonucci (2005), no sentido de escutar as crianças, estando ao lado delas, sem pressa, permitindo o erro, mas, principalmente, estabelecendo uma relação em que elas se sintam empoderadas e confiantes para expressarem das mais diferentes formas suas ideias, em que o(a) docente possa escutar para além do audível, sabendo que as crianças podem trazer não apenas respostas, mas também perguntas.

Durante o processo desenvolvido houve muitas descobertas sobre as hipóteses, teorias, pensamentos, críticas, sugestões; vozes das crianças que surpreenderam o olhar dos(as) adultos(as), pois as crianças se mostraram mais capazes do que eles(as) imaginavam: seus olhares amplos e sugestivos para soluções, não pensando apenas em seu próprio bem estar, mas para um coletivo, como se veri- 
fica na fala de duas crianças: "tem que colocar cimento nos buracos, para o bebê não cair" ou "tem que colocar uma proteção para nós não cair".

A escuta sensível às vozes das crianças, firmada em uma relação horizontal, confiante e centrada nos problemas do contexto, "[...] onde formem hábitos de solidariedade e de participação" (FREIRE, 2001, p. 91), denota que meninos e meninas ao proporem mudanças e melhorias para os espaços da creche, as projetam para o coletivo, priorizando o bem comum. Esta preocupação das crianças com o bem comum também é retratada por Tonucci (2005) através do projeto "A cidade das crianças", em que meninos e meninas participam de discussões que visam a melhoria das cidades, projetando espaços públicos para todos e todas. Verifica-se, portanto, que:

As crianças são capazes de intervir, expressando opiniões e fazendo propostas a respeito de todos os problemas [...], porque elas também ali vivem, como cada cidadão, e ali vivem a partir de seu próprio ponto de vista particular que é, ao mesmo tempo, mais "baixo" e mais ignorado do que o dos outros. (TONUCCI, 2005, p. 20-21)

Essa vivência das crianças na creche a partir de seu próprio ponto de vista, permitiu à elas apontarem dificuldades que os(as) professores(as) não tinham a dimensão do quanto eram percebidas como barreiras para as crianças, como, por exemplo, na área externa: "precisa de cimento, têm as pedras, ai a motoca para"; "tem que colocar um vidro no chão para melhorar" e "não gosto da motoca, tem buraco e não dá pra eu correr". Esse diálogo, estabelecendo uma relação de descobertas e aprendizagens entre as docentes e as crianças implica " [...] escutar como forma de aceitar de bom grado e estar aberto às diferenças, reconhecendo o valor do ponto de vista e da interpretação dos outros" (RINALDI, 2014, p. 124).

Inicialmente os(as) professores(as) acreditavam que os espaços elegidos pelas crianças, como um lugar que elas gostavam, não precisariam de ajustes, e, pelo contrário, como revela o relato de uma criança ao avaliar a sala de vídeo: "eu acho que ela tá ruim, tem que tirar essas cadeiras e colocar mais tapetes, e TV não tá prestando; outra 
criança também pontua “tá faltando lugar", ao se referir a quantidade de cadeiras naquele espaço. Com relação ao refeitório, identificam esse espaço como um lugar onde, "a gente senta pra comer e beber suco", e outra criança pontua que não gosta, discordando de uma outra criança, "pra mim não tá bom, porque não tem espaço".

Durante esse processo, as crianças foram sentindo-se confortáveis e seguras de exercer o direito de dizer a sua palavra, pois “[...] se dizer a palavra verdadeira, que é trabalho, que é práxis, é transformar o mundo, dizer a palavra não é privilégio de alguns homens, mas direito de todos os homens" (FREIRE, 1987, p. 78), a fim de pronunciar o mundo, referindo ao contexto da creche, pronunciando suas inquietudes para promover transformações.

A partir do processo de autoavaliação institucional, as crianças puderam vivenciar situações de discordâncias de opiniões, e aprender que cada um(a) traz para o diálogo sua visão de mundo, e que não é obrigado a concordar com a opinião do(a) colega, mas é preciso respeitá-lo, pois diante de um processo dialógico e democrático o sujeito expõe seu ponto de vista não inibindo a possibilidade de discordância, mas criando relações respeitosas, em que todos(as) possam aprender e ensinar, pois ninguém sabe tudo ou não sabe nada (FREIRE, 1987).

Durante este processo de avaliação, as crianças lembraram que a diretora iria comprar o que elas haviam solicitado, então sugeriram a compra de outros brinquedos por meio de reinvindicações, como: "não dá pra brincar de casinha só com panelinha", "quero um brinquedo que eu entro de um lado e saiu do outro", "não tem brinquedo para eu brincar. Falta balança, porque o Luis não deixa eu brincar, ai tem que ter outra".

Ao finalizar o processo de autoavaliação institucional com as crianças, a direção replanejou os gastos das verbas municipais e federais, a fim de efetivar as propostas apontadas pelas crianças. Diante disso, como afirma Freire (1997, p. 60):

É preciso e até urgente que a escola vá se tornando um espaço acolhedor e multiplicador de certos gostos democráticos como o de ouvir os outros, não por puro favor mas por dever, o de respeitá-los, o da tolerância, o do 
encantamento às decisões tomadas pela maioria a que não falte contudo o direito de quem diverge de exprimir sua contrariedade. O gosto da pergunta, da crítica e do debate.

Após concretizar as ações, as crianças foram reunidas no refeitório da creche para a apresentação, através de fotos, das mudanças ocorridas na instituição, demonstrando a importância e legitimação às suas vozes, pois ao respeitar as crianças como sujeito de direitos, dentre eles o direito de dizer sua palavra, por meio de uma relação respeitosa, pedindo sua permissão, consentimento, explicando os motivos de sua participação, desvelando seus porquês, construindo caminhos juntos, e, principalmente, partilhando resultados, demonstra "[...] que aquilo que fizeram tem valor, tem significado, e assim elas descobrem que 'existem' e podem sair do anonimato e da invisibilidade, observando que aquilo que dizem e fazem tem importância, é ouvido e apreciado: é um valor" (RINALDI, 2014, p.136).

\section{Considerações finais}

Ao analisar o processo de autoavaliação institucional participativa no espaço da creche, considerando as vozes das crianças pequenas, pode-se compreender a epistemologia freiriana que assume a criança como um sujeito de direitos, dentre eles o direito à participação em processos decisórios e o direito de pronunciar a sua palavra. É possível, também, reconhecer a creche como um lugar de encontros, em que meninos e meninas podem viver experiências democráticas e dialógicas, a partir de relações entre adultos(as) e crianças marcadas pelo respeito, confiança, amorosidade e escuta, em que ambos são aprendizes.

A experiência vivenciada pelas crianças e professoras da creche em tela, rompeu com a distância entre discursos em defesa da criança participativa e potente e práticas centradas no adulto(a) em uma perspectiva bancária (FREIRE, 1987), pois a formação de cidadãs e cidadãos se constitui no exercício da cidadania, em que meninos e meninas constroem uma leitura crítica da realidade e vão se constituindo enquanto sujeitos transformadores da sociedade. 
A educação infantil, como primeira etapa da educação de meninos e meninas, precisa construir ambientes educativos que primem pelo exercício democrático, cuja a participação ativa das crianças, também nos processos de decisão, seja uma constante no cotidiano de creches e pré-escolas. Nesse sentido, os(as) educadores(as) são desafiados(as) a descentrarem-se da hegemonia adultocêntrica, para que, desde uma perspectiva dialógica, possam estimular às crianças no desvelamento e reinvenção do mundo. Um mundo com mais "boniteza" e justiça social.

\section{Referências}

BONDIOLLI, Anna (org.). O projeto pedagógico da creche e sua avaliação: a qualidade negociada. Campinas: Autores Associados, 2004.

BRASIL. Constituição da República Federativa do Brasil. Promulgação de 1988. Brasília: Senado Federal, 1988.

BRASIL. Decreto $\mathbf{n}^{\mathbf{9}} \mathbf{9 9 . 7 1 0}$, de 21 de novembro de 1990. Promulga a Convenção sobre os direitos da criança. Diário oficial da União. Brasília, 1990.

BRASIL. Ministério da Educação. Secretaria de Educação Básica. Diretrizes Curriculares Nacionais para a Educação Infantil. Secretaria de Educação Básica. Brasília: MEC, SEB, 2010.

DELGADO, Ana C. Coll. A emergência da Sociologia da Infância em Portugal. Revista Educação Cultura e sociologia da Infância. Revista Educação: Cultura e Sociologia da Infância. A criança em foco. São Paulo: Segmento, 2013, p. 14-27.

FREIRE, Paulo. Carta a Loris Malaguzzi. In: FARIA, Ana Lúcia G. de; SILVA, Adriana A. Por uma nova cultura da Infância. Revista Educação: Cultura e Sociologia da Infância. A criança em foco. São Paulo: Segmento, 2013, p. 98-111.

FREIRE, Paulo. Educação e atualidade brasileira. São Paulo: Cortez/IPF, 2001.

FREIRE, Paulo. Pedagogia da autonomia: Saberes necessários à prática educativa. 5. ed. Rio de Janeiro: Paz e Terra, 1996.

FREIRE, Paulo. Pedagogia da esperança: um reencontro com a pedagogia do oprimido. Rio de Janeiro: Paz e Terra, 1992. 
FREIRE, Paulo. Pedagogia do oprimido. 17. ed. Rio de Janeiro: Paz e Terra, 1987.

FREIRE, Paulo. Professora sim, tia não: cartas a quem ousa ensinar. São Paulo, Olho D'água, 1997.

FREIRE, Paulo; GUIMARÃES, Sérgio. Sobre educação: diálogos. Rio de Janeiro: Paz e Terra, 1984. (V. 2)

FREIRE, Paulo; FAUNDEZ, Antônio. Por uma pedagogia da pergunta. 8. ed. Rio de Janeiro/São Paulo: Paz e Terra, 2017.

GADOTTI, Moacir. (org.). Paulo Freire: uma bibliografia. São Paulo: Cortez: Instituto Paulo Freire; Brasília, DF: UNESCO, 1996.

LARROSA, Jorge. Pedagogia Profana: danças, pirueta e mascaradas. $4^{\mathrm{a}}$ ed. Belo Horizonte: Autêntica, 2003.

OSTETTO, Luciana E. Observação, registro, documentação: nomear e significar as experiências. In: OSTETTO, Luciana Esmeralda (org.). Educação Infantil: saberes e fazeres da formação de professores. $5^{\text {a }}$ ed. Campinas, SP: Papirus, 2012, p. 13-32.

SÃO PAULO. Indicadores de Qualidade da Educação Infantil Paulistana. São Paulo: SME/DOT, 2016.

RINALDI, Carla. Diálogos com Reggio Emilia: escutar, investigar e aprender. 2. ed. São Paulo: Paz e Terra, 2014.

ROSA, Emillyn. O planejamento democrático e participativo construído com crianças de 0 a 3 anos. 2015. Dissertação de Mestrado. Universidade Nove de Julho. UNINOVE de São Paulo.

SARMENTO, Manuel J.; FERNANDES, Natália; TOMÁS, Catarine. Políticas Públicas e Participação Infantil. Revista Educação, Sociedade e Culturas. Porto, Portugal. n. 25, p. 183-206, 2007.

SILVA, Marta R. P. da. Infância e cidadania: diálogo de inspiração em Paulo Freire. 2020. (no prelo).

SILVA, Marta R. P. da. Por uma educação infantil emancipatória a vez e a voz das crianças e de suas professoras. Cadernos de Educação. Dossiê, n. 58, p. 83-100, 2017. Disponível em: https://periodicos.ufpel.edu.br/ojs2/index.php/caduc/article/view/12370. Acesso em 10 mai/2020. 
SILVA, Marta R. P. da; MARQUES, Renata F. B. Os círculos de cultura na educação infantil: construindo práticas pedagógicas dialógicas. Educação, Santa Maria, v. 44, p. 1-24, 2019. Disponível em: https://periodicos.ufsm.br/reveducacao. Acesso em $10 \mathrm{mai} / 2020$.

TONUCCI, Francesco. Quando as crianças dizem: agora chega! Porto Alegre: Artmed, 2005. 